\title{
A Hybrid Approach for Dynamic Simulation of Safety Risks in Mega Construction Projects
}

\author{
Na Xu $\mathbb{D}^{1},{ }^{1}$ Qing Liu $\left(\mathbb{D},{ }^{2}\right.$ Ling Ma $\mathbb{D}^{3},{ }^{3}$ Yongliang Deng $\mathbb{D}^{1},{ }^{1}$ Hong Chang, Guodong Ni ${ }^{1},{ }^{1}$ \\ and Zhe Zhou ${ }^{4}$ \\ ${ }^{1}$ School of Mechanics \& Civil Engineering, China University of Mining and Technology, Xuzhou 221116, China \\ ${ }^{2}$ School of Civil Engineering, Xuzhou University of Technology, Xuzhou 221000, China \\ ${ }^{3}$ Bartlett School Construction and Project Management, University College London, London WC1E7HB, UK \\ ${ }^{4}$ China Construction South Investment Co. Ltd., Shenzhen 518000, China
}

Correspondence should be addressed to Qing Liu; liuqingcumt@126.com

Received 10 February 2020; Revised 13 June 2020; Accepted 6 October 2020; Published 23 October 2020

Academic Editor: Dong Zhao

Copyright (c) $2020 \mathrm{Na} \mathrm{Xu}$ et al. This is an open access article distributed under the Creative Commons Attribution License, which permits unrestricted use, distribution, and reproduction in any medium, provided the original work is properly cited.

\begin{abstract}
Mega construction projects (MCPs) are inherently high-risk and complex. The challenge of safety management for mega construction projects is that safety risk factors constantly change and interact with each other in the long-term construction period. Few of the prior studies have enabled the prediction of the safety state in a dynamic and connected overview, which is a critical characteristic of safety risks in MCPs. Therefore, a hybrid approach for the dynamic simulation of risk factors is proposed. A three-stage procedure review of explicit documents, including accident investigation reports and construction standards, was carried out to identify safety risk factors and the causal relationships among them. Subsequently, the likelihood exposure and consequence (LEC) assessment method was applied to define the changes in risk factors over time. A system dynamics (SD) model was established to integrate the interacting risks and simulate the developing trend of the overall safety risk state. Moreover, a sensitivity analysis was provided to rank risk factors and simulate optimal risk mitigation strategies. Finally, the model was applied to the urban rail transit Line 9 project in China as a case study. The results indicated that the proposed hybrid approach performed satisfactorily under complex interrelated risk factors. Therefore, this study provides a practical framework to simulate and predict the safety state dynamically in a timely process for MCPs, either ahead of a project theoretically or during a project with real data.
\end{abstract}

\section{Introduction}

Mega construction projects (MCPs) involve large investments, typically $\$ 1$ billion or more [1] and exert a profound influence on the local society and economy [2]. MCPs are characterized by their complexity, uncertainty, ambiguity, dynamic interfaces, and longer time periods required for completion, which give rise to great risks during the project life cycle [3]. Despite advances in safety risk analysis and risk control strategies, accidents still occur, resulting in serious social impact, heavy casualties, and huge economic losses $[4,5]$. Numerous studies have mentioned that risk-based analysis is an effective solution for accident prevention and control [6]. Based on the theory of accident causation, a safety accident is a result of the interaction between risk factors [7]. Moreover, these risk factors are not stable and independent; instead, they constantly change and interact with each other throughout the construction period [8]. However, as $\mathrm{Na}$ [9] and Hallowel et al. argued [10], a few of these prior works evaluated the interactions between risk factors and thus failed to predict the safety state in a dynamic and connected way. Therefore, a deeper understanding of the underlying risk system in MCPs is required in order to manage the safety risks effectively.

Against this contextual backdrop, this paper commences with a brief review of safety risk models and dynamic simulation models for MCPs. Later, a hybrid approach, which combines the likelihood exposure and consequence (LEC) assessment method and system dynamics (SD) model, is provided. Finally, the implementation of the developed model in an urban rail transit construction project in Shenzhen, China, is discussed. 


\section{Literature Review}

2.1. Safety Risk Models for Mega Construction Projects. Several studies concerning safety risk models for MCPs have been conducted over the past two decades; these can be roughly divided into two stages. In the first stage, most of the analysis models assumed that the risk factors were independent. The prioritization of risk factors was ranked by their individual risk value, and the risk state was calculated as the weighted sum of all factors. The analysis models included the analytic hierarchy process (AHP)/fuzzy AHP [11], failure model and effects analysis (FMEA)/fuzzy-FMEA [12], fault tree analysis (FTA) [13], technique for order preference by similarity to an ideal solution (TOPSIS) [14], entropy theory [15], Monte Carlo (MC) simulation [16], principal component analysis (PCA) [17], and factor analysis (FA) [18].

Furthermore, with the evolution of systems thinking since the 1990s [19], risk relationships [20], risk interactions [10], risk transfer [21], and similar concepts have been introduced. A study on safety risk models was developed into the second stage, during which the relationships among safety risk factors were considered to evaluate the safety state based on the importance of those factors. Various analysis models have been applied to solve the interrelationships among safety risk factors. Two methods, structural equation modeling (SEM) and interpretation structural modeling (ISM), have been used to determine the interrelationship among safety risk factors. ISM aims to construct the hierarchy structure of the factors based on their direct and indirect correlation paths. For instance, in [9], a threelayered structure, including root risks, indirect risks, and direct risks were proposed based on the pairwise comparison matrices. The application is qualitative and is limited by the number of risk factors, which, if increases, will result in power level growth of the experts' judgment of pairwise comparison. SEM aims to capture the direct and indirect impacts among factors. For example, Li et al. conducted SEM to clarify the correlation paths among safety risk factors of high-rise buildings [22]. However, this method is based on statistical analysis and thus requires an enormous sample size [23]. Another research trend is to assess the strength of the interrelated linkage using node degree calculated through techniques such as a complex network (CN) $[24,25]$, social network analysis (SNA) [26], and decisionmaking trial and evaluation laboratory (DEMATEL) [27]. These methods perform satisfactorily at selecting critical safety risk factors from the perspective network linkage, whereas these are unsuitable for the evaluation of safety state according to the interactions between different factors.

To address the assessment of risk state for MCPs, methods such as the analytic network process (ANP) and Bayesian belief network (BBN) have been widely utilized for conducting quantitative analyses. The ANP method is based on AHP. It uses the pairwise comparison matrix to weight the importance of risk factors and uses the sum value to measure the overall level of safety risk. Wu et al. adopted fuzzy ANP to assess the critical risk factors and quantify the total risk rank of a subway station construction through the synthesis of these weight matrices [28]. Similar to the ISM, the pairwise comparison requires much more computation if risk factors increase [29]. A Bayesian belief network (BBN) combines graph theory and probability theory to evaluate the risk state based on the conditional probabilities of the nodes [30]. Liu et al. created a Bow-Tie-Bayesian network approach to determine the key causes of excessive surface settlement and predict the probability of surface collapse [31]. BBN is a powerful method to model complex risk interrelationships for MCPs because of its simplicity and precision; however, it can only deal with discrete functions [29]. In addition, hybrid methods that combine multiple methods, for example, the combination of DEMATEL and $\mathrm{BBN}$ in [32], are emerging to solve the complex issues for the construction of megaprojects.

In recent times, data mining, text mining, natural language processing (NLP), machine learning, artificial intelligence (AI), building information modeling (BIM), Internet of Things (IoT), and the use of sensors and robotics are frequently utilized in the contemporary risk analysis models to enhance the level of automation and improve the algorithm efficiency [33-36]. For example, Shin et al. applied the stochastic gradient boosting algorithm to learn from 16,248 construction accident cases in Korea [37].

Nevertheless, the above analysis models are generally network-based, and the relationships of risk factors are evaluated based on the topology analysis of the network. None of these approaches enable a dynamic and holistic analysis, and thus, they fail to describe the variations in risk factors, which is a natural characteristic of safety risks in MCPs. In addition, these models cannot provide predictions about safety states during the entire life cycle under different risk control measures, which is required for optimizing the risk control strategies.

2.2. Dynamic Simulation Models Based on SD. Owing to its outstanding advantages in simulating a dynamically complex system that is constantly changing, tightly coupled, and nonlinear [38], the system dynamics (SD) model has been implemented recently to simulate the risks in MCPs. Moreover, it has proven its value by significantly improving the project performance [39]. As such, De Marco analyzed the stakeholder's behavior with the SD model in complex EPC projects and described the multiple influences of the main project participants on decision-making problems [40]. Moreover, Love et al. adopted this model to describe how unplanned changes could impact the progression of work and observed major factors influencing a project's performance [41]. Gabo and Zhao established an SD model to predict the evolutionary process of game players' behavioral strategies in China's new energy power construction PPP project and obtained the key factors that affected the stability of these strategies [42]. As another example, Nasirzadeh et al. built an SD model for safety risk distribution in a pipeline construction project, which reduced safety management costs by 3.7\% [43]. Thus, the SD model has clearly exhibited its capability to cope with complex risk problems in the construction industry. However, few studies have applied the SD model to predict the safety risk for MCPs. 
The SD model follows the principle that all systems have a structure, and the system structure determines the system function [44]. Before simulating, the variables and equations that describe the system structure must be determined. Historical data has proven useful for constructing SD models based on statistical methods, such as regression analysis [45]. However, owing to the lack of historical data on safety risk factors, it is challenging to describe the required parameters in functions and equations. Some previous works in the area of safety risk simulation defined variables via interviews in a cyclic manner. For instance, to create a causal loop diagram in a mass rapid transit (MRT) tunneling project in Singapore, Guo et al. counted the frequency of unsafe behaviors and used semistructured interviews to perceive the influence of various factors [46]. In addition, Nasirzadeh et al. combined fuzzy logic and SD models to address the imprecise and uncertain nature of risks; additionally, interval arithmetic was employed in the SD simulation model [47]. Moreover, Wang et al. established an SD model to evaluate safety risks in tunnel construction projects to determine an appropriate tradeoff between production and protection goals. BBNs and smooth relevance vector machines were developed to describe the interactions between a contractor's organizational and technical systems [48]. Taken together, previous studies have provided an important insight that interval data helps to build a SD model.

In summary, there has been inadequate research on dynamic simulation models to reveal the fundamental mechanisms of safety risks in MCPs. The most challenging part of dynamic simulation for safety risks lies in the following: (1) identification of risk factors and their causal relationships and (2) quantification of variations in risk factors over the construction period. Therefore, a hybrid approach, which combines the LEC method and the SD model, is proposed to overcome the above challenges.

\section{Methods}

Owing to the complexity of MCPs, safety risk factor identification involves several departments and knowledge-rich experts. It is inefficient and time-consuming to collect information relying only on questionnaires and expert interviews. Therefore, in this study, we conducted in-depth document reviews instead, to explore the safety risk factors. Specifically, safety accident investigation reports, construction standards, and regulations were used as data sources as these documents usually contain detailed information about safety risk factors and their causal relationships. The workflow of the safety risk simulation is depicted in Figure 1. Initially, a three-stage procedure was created to identify safety factors and their causal relationships. Subsequently, the LEC method was applied to define the variables and equations that were needed in the SD model. Finally, an SD model was established for the prediction of the safety state level and sensitivity analysis of the safety risk factors.
3.1. Identification of Safety Risks. A three-stage procedure for risk factor identification was designed as follows:

(1) The first stage collected candidate items of risk factors. The words and phrases in the documents, containing reasons that caused an accident or might have caused an accident, were identified and extracted by domain experts as candidate items of risk factors.

(2) The second stage grouped all the candidate items based on their risk categories. This grouping was carried out by domain experts according to their contextual descriptions in the text. The set of risk categories was defined as a set $I$.

(3) The third-stage analysis created the risk factors. Candidate items within a category were randomly divided into two parts. One of these was used for concept induction, and another part was used to verify whether the inducted concepts were saturated. If an item did not match the existing concepts, it implied that the creation of a new concept was required to describe that item. This stage aimed to reduce the data by grouping similar candidate items into major themes.

Risk factor relationships were identified through literature review and expert interviews. Relationships were first extracted from existing documents, including accident investigation reports, standards, and regulations. Later, the relationships in which one factor had possibly interconnected with other factors were verified through expert interviews.

To ensure the rigor of risk factors and their relationships, all analyses were performed by two trained domain experts, and one additional domain expert reviewed the results. These experts are experienced construction professionals. All discrepancies were discussed and resolved by all experts through consensus.

3.2. Definition of Variables and Equations. LEC is a semiquantitative evaluation method for estimating the operational risks in potentially hazardous environments $[49,50]$. It is used for quantifying the safety risk values. For $i=1,2, \ldots, n$, the safety level $\left(\mathrm{SL}_{i}\right)$ of the risk factor $i$ is calculated based on the data collected from a field study, as expressed in the following equation [51]:

$$
\mathrm{SL}_{i}=L_{i} \times E_{i} \times C_{i},
$$

where $L_{i}$ is the probability of the occurrence of risk factor $i$ during the construction period, $E_{i}$ refers to the frequency of exposure to a hazardous environment, and $C_{i}$ is the loss incurred as a consequence of the accident.

One of the central tenets of the SD model is the variation in risk factors over time. By conducting regular evaluations based on equation (2) over the time interval $\Delta t$, the change rate of the risk factor $R_{i}$ can be easily calculated by dividing the difference observed during the two evaluations by the time interval $\Delta t$ : 


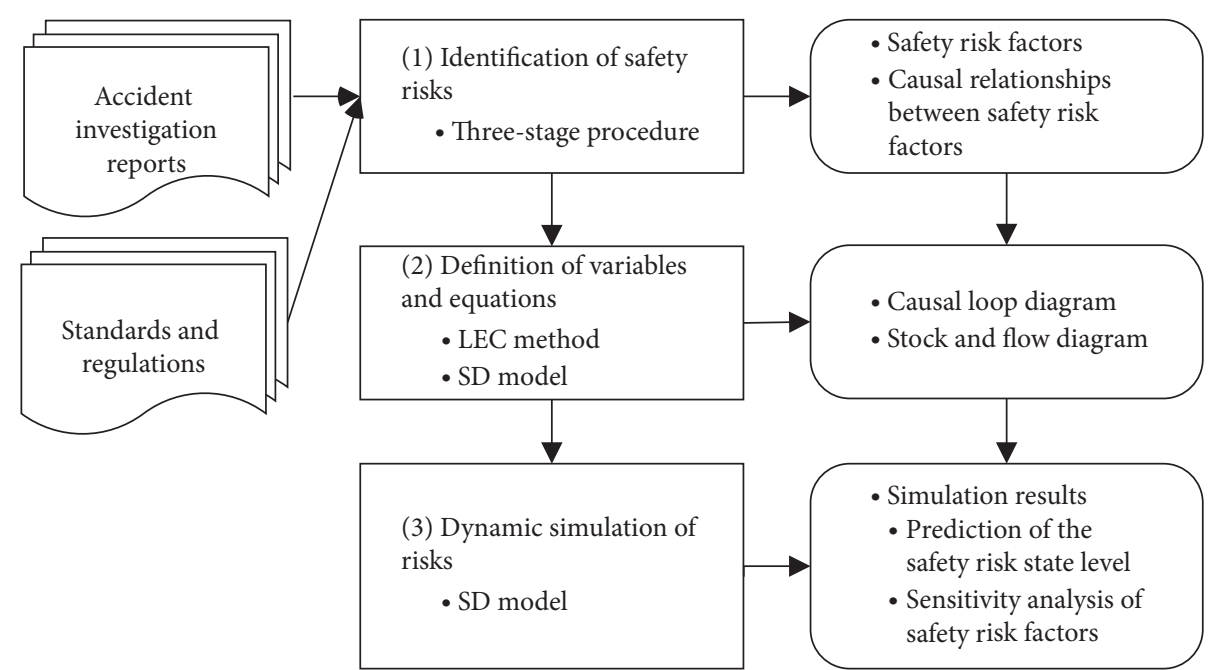

FIGURE 1: Workflow of safety risk simulation.

$$
R_{i}=\left[\frac{\left(\mathrm{SL}_{i}(t)-\mathrm{SL}_{i}(t-\Delta t)\right)}{\Delta t}\right],
$$

where $\Delta t$ is the unit time-step, $\mathrm{SL}_{i}(t)$ is the safety level of the factor $i$ at time $t$, and $\mathrm{SL}_{i}(t-\Delta t)$ is that at the time $t-\Delta t$.

Furthermore, safety risk factors influence and are influenced by other factors in MCPs. Based on the results of Li et al. [52], the risk transfer coefficient, which depends on the changes in its previous factors, was added to correct $R_{i}$. Therefore, the corrected change rate $R_{i}^{\prime}$ can be obtained using the following equation:

$$
R_{i}^{\prime}=\left[\frac{\left(\mathrm{SL}_{i}(t)-\mathrm{SL}_{i}(t-\Delta t)\right)}{\Delta t}\right]\left[\frac{\mathrm{SL}_{h}(t)}{\mathrm{SL}_{h}(t-\Delta t)}\right],
$$

where $\mathrm{SL}_{h}$ is the safety level of factor $h$, which has a causal influence on the factor $i$. $\left(\mathrm{SL}_{h}(t) / \mathrm{SL}_{h}(t-\Delta t)\right)$ implies the risk transferred to factor $i$ through the influence of factor $h$.

3.3. Dynamic Simulation of Risks. The modeling simulation begins with the description of the safety risk system of MCPs in a causal loop diagram. Each relationship is illustrated with arrows marked positive $(+)$, if they are mutually reinforcing, and negative (-), if they are contradictory [53]. Subsequently, the causal loop diagram is developed into a stock and flow diagram, in which, a formulation for each variable is provided based on the predetermined equations (1)-(3).

3.3.1. Developing Trends in Safety Risk State Level. The levels of a variable at time $t$ can be calculated as the sum of its $S L$ at time $t-\Delta t$ and the variation in its value during $\Delta t$, as expressed in the following equation:

$$
\mathrm{SL}_{i}(t)=\mathrm{SL}_{i}(t-\Delta t)+R_{i}^{\prime} \times \Delta t
$$

The safety state level of risk category SLI $(t)$ can be calculated using equation (5), where $Q Z_{i}$ refers to the weight of factors $i$. The overall safety state level SL $(t)$ is quantified by equation (6), where $Q Z_{j}$ refers to the weight of risk category $j$. The risk category $j(j \in I)$ is obtained in Section 3.1:

$$
\begin{aligned}
& \operatorname{SLI}(t)=\sum_{i}^{n} \mathrm{QZ}_{i} \times \mathrm{SL}_{i}(t), \\
& \mathrm{SL}(t)=\sum_{j}^{m} \mathrm{QZ}_{j} \times \mathrm{SLI}_{j}(t) .
\end{aligned}
$$

The change rates $\mathrm{RI}_{j}$ of each factor category can be obtained using the following equation:

$$
\mathrm{RI}_{j}=\sum_{i}^{n} \mathrm{Q} Z_{i} \times R_{i}^{\prime}
$$

3.3.2. Sensitivity Analysis of Safety Risk Factors. To optimize risk control strategies, a sensitive value is defined to reveal the influence of the factor on the overall safety state. As provided in equation (8), the sensitive value $S_{i}$ reflects the change in the overall safety state level while one factor increases by one and the other factor remains unchanged. Therefore, the contributions of each risk factor can be quantified and the results can be used to determine the most effective risk control strategy. The more sensitive a factor is, the higher its priority is:

$$
S_{i}=\sum_{0}^{T}\left[\frac{\left|\left(\mathrm{SL}_{t B i}-\mathrm{SL}_{t A i}\right)\right|}{\left(T \times \mathrm{SL}_{t B i}\right)}\right] .
$$

$\mathrm{SL}_{t B i}$ is the safety risk state value affected by the risk factor $i$ at time $t$ before changing, $\mathrm{SL}_{t A i}$ refers to the safety risk state value at time $t$ after increasing one unit of risk factor $i$, and $T$ refers to the entire simulation time (i.e., construction period of megaprojects).

\section{Experiments and Results}

4.1. Materials and Data Sources. As one of the most important investments, urban rail transit construction projects are typical MCPs. As stated in the $13^{\text {th }}$ Five-Year 
Plan for Economic and Social Development of the People's Republic of China, the construction of large-capacity public transportation and green travel will be prioritized [54]. Moreover, the plan to increase the urban rail transit (URT) operating mileage to $3,000 \mathrm{~km}$ is designated as one of the top 100 projects under China's national strategy. China's operating mileage is set to reach approximately $6,000 \mathrm{~km}$ by 2020 , marking the rapid construction and development of the country's URT. Therefore, China's URT network was accelerated in the past five years and will maintain a fast-paced development. However, several accidents occur during the rapid development process. It is specified in the Code for risk management of underground works in urban rail transit (GB 50652-2011) that dynamic risk assessment must be conducted to avoid accidents, casualties, property damage, and environmental destruction [55].

The urban rail transit Line 9 project in Shenzhen was considered as a case study. Shenzhen is China's first special economic zone and is undergoing rapid population growth. To relieve traffic pressure, the Line 9 project was planned with a $25 \mathrm{~km}$ underground tunnel and 22 stations. The total investment was approximately $\$ 7$ billion. In this study, 168 accident reports were collected from web portals, including the State Administration of Work Safety, Ministry of Housing and Urban-Rural Development (MOHURD), and other related administrative departments in different cities and provinces across China. By interviewing and investigating construction companies, 48 more unpublicized accident reports were collected. Therefore, a total of 216 accident reports were gathered from 30 cities, which accounted for $86 \%$ of China's cities with rail transit. By the end of 2018 , 35 cities in China were served by rail transit.

Furthermore, 14 construction standards and regulations closely related to safety risks of URT were collected as a supplement to data sources. These include the Code for design of metro (GB 50157-2013), Code for geotechnical investigations of urban rail transit (GB 50307-2012), and the Code for risk management of underground works in urban rail transit (GB 50652-2011). Specifically, these standards and regulations cover the investigation, design, and construction phases of the URT project. The list of construction standards and regulations is provided in Table 1.

4.2. Safety Risk Factors. An in-depth review of the collected documents was carried out according to the procedures described in Section 3.1. Figure 2 details the three-stage procedure for risk factor identification. During the first stage analysis, 741 safety risk items were extracted through document analysis. Subsequently, in the second stage analysis, these candidate items were grouped into five categories considering 4M1E theory [56]: investigational factors $(K)$, design factors $(S)$, technological factors $(J)$, managerial factors $(G)$, and environmental factors $(H)$. Therefore, the set $I$ includes five elements: $I=\{K, S, J, G, H\}$. Of the 741 items, 53 were classified as investigational factors, 68 items were design factors, 246 were technological factors, 272 were managerial factors, and 102 were environmental factors.

Consider the investigation category as an example of the third-stage analysis, as shown in Table 2. 53 candidate items were randomly divided into two groups with 27 and 26 items, respectively, and were analyzed by two trained researchers. Using group one, three main themes were induced: completeness in the degree of investigation, accuracy of investigation, and timely additional investigation. Group two was used for verification. The results showed that all items in group two could be inducted into the former concepts, indicating that the three concepts were saturated. In the end, 28 candidate items were inducted as "completeness in the degree of investigation $\left(K_{1}\right)$," 10 candidate items as "accuracy of investigation $\left(K_{2}\right)$," and 15 as "timely additional investigation $\left(K_{3}\right)$." The results were checked by an additional researcher to ensure there were no discrepancies.

Similarly, all the candidate items in one category were organized at a higher level of abstraction. Finally, a list of 29 safety risk factors emerged. These are provided in Table 3.

4.3. Causal Relationships between Safety Risk Factors. Owing to the dynamic nature of risks in MCPs, safety risk factors interact with each other through casual relationships. Based on the literature review, these relationships were first extracted by two domain experts and were then checked by a third one to ensure their accuracy.

Considering the risk categories, the hydrogeological environment and the existing buildings and structures in the project area should be investigated. The Code for investigation of geotechnical engineering (GB 50021-2009) has clear specifications for inspection of various factors such as topography, landform, stratum, and geotechnical properties. However, the underground geological environment is extremely complex to investigate and predict. Therefore, adverse environmental conditions increase the complications in carrying out the investigation work, that is, environmental factors influence investigation factors (environment $(H) \longrightarrow$ investigation $(K)$ ). The designer shall conduct their design according to the investigation reports, meaning that inaccurate investigation information leads to a deficiency in design drawings (investigation $(K) \longrightarrow$ design $(S)$ ). Contractors perform the construction process according to drawings that are within the constraints of safety risk management. They should also choose suitable construction methods and adjust construction parameters based on the specific environmental characteristics (environment $(H)$, investigation $(K)$, design $(S)$, and management $(G) \longrightarrow$ technology $(J))$. According to the above relationships, a causal loop diagram of risk factor categories was established, as shown in Figure 3.

In terms of investigation factors, the frequent interactions among groundwater, rock, and soil make the underground environment difficult to predict. Therefore, the more detailed information provided by the investigation, the more accurate the investigation reports (completeness in the degree of investigation $\left(K_{1}\right) \longrightarrow$ accuracy of investigation $\left(K_{2}\right)$ ). An 
TABLE 1: Construction standards and regulations used in the case study.

\begin{tabular}{lccc}
\hline Number & Type & Issue number & Name of the standard or regulation \\
\hline 1 & National standard & GB 50157-2013 & Code for design of metro \\
2 & National standard & GB 50307-2012 & Code for geotechnical investigations of urban rail transit \\
3 & National standard & GB 50490-2009 & Technical code of urban rail transit \\
4 & National standard & GB 50652-2011 & $\begin{array}{c}\text { Code for risk management of underground works in urban rail transit } \\
\text { Standard for construction safety assessment of metro engineering }\end{array}$ \\
5 & National standard & GB 50715-2011 & Code of project management for urban rail transit construction \\
6 & National standard & GB 50722-2011 & Code for monitoring measurement of urban rail transit engineering \\
7 & National standard & GB 50911-2013 & Code for investigation of geotechnical engineering \\
8 & National standard & GB 50021-2009 & Technical code of urban rail transit engineering safety control \\
9 & National standard & GB/T 50839-2013 & project \\
10 & Departmental regulation & Jianzhi (2010) no. 5 & Interim measures of safety and quality management for urban rail transit \\
11 & Departmental regulation & Jianzhi (2016) no. 173 & Guide for safety and quality inspection for urban rail transit project \\
12 & Industry standard & AQ 8004-2007 & Detailed rules for safety preevaluation of urban rail transit \\
13 & Industry standard & AQ 8005-2007 & Detailed rules for safety assessment of urban rail transit \\
14 & Industry standard & AQ 8007-2013 & Safety evaluation standard on trial operation of urban rail transit \\
\hline
\end{tabular}

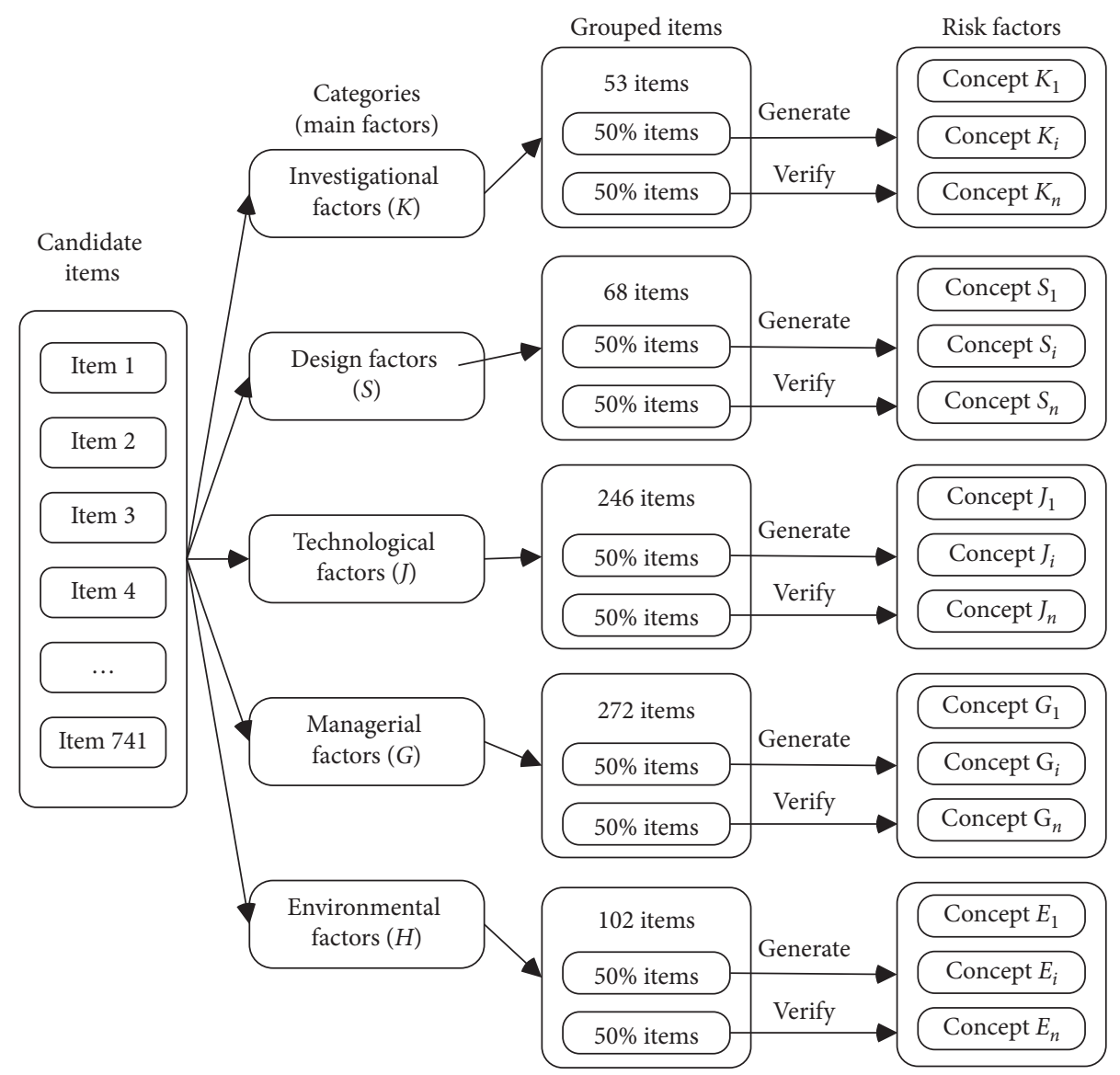

FIGURE 2: Three-stage procedure for risk factor identification.

additional investigation of the key areas and changed areas could ensure construction safety (timely additional investigation $\left(K_{3}\right) \longrightarrow$ accuracy of investigation $\left(K_{2}\right)$ ). For design factors, the Code for design of metro (GB 50157-2013) stipulated the obligatory items, calculation methods, and empirical values in the design process of urban rail transit (rationality of design calculation $\left(S_{2}\right) \longrightarrow$ integrity of the design $\left(S_{11}\right)$ ). In addition to the requirements of the function, a project's structure should be strong and stiff enough to ensure safety. Generally, the structural calculation is based on statistical analysis and empirical treatment of the borehole data. To make the design more reasonable and complete, designers should conduct on-the-spot surveys to determine the accuracy of the survey data (consideration of the on-site 
TABle 2: Three-stage procedure for identifying investigation factors.

\begin{tabular}{|c|c|c|}
\hline First-stage (candidate items) & Second stage (category) & Third-stage (risk factors) \\
\hline $\begin{array}{l}\text { Ignoring hydrogeological exploration } \\
\text { Ignoring pipeline inspection before excavation } \\
\text { for foundation } \\
\text { Failure to discover and remove underground obstacles } \\
\text { Failure to discover underground shelters } \\
\text { Lack of advanced forecast of geological conditions } \\
\text { Lack of detailed information on existing building structures }\end{array}$ & Investigational factors & $\begin{array}{l}\text { Completeness in the degree } \\
\text { of investigation }\end{array}$ \\
\hline $\begin{array}{l}\cdots \\
\cdots \cdots \\
\cdots \cdots\end{array}$ & & $\begin{array}{l}\text { Accuracy of investigation. } \\
\text { Timely additional investigation }\end{array}$ \\
\hline
\end{tabular}

TABLE 3: List of safety risk factors.

\begin{tabular}{|c|c|c|}
\hline Categories & Code & Factors \\
\hline \multirow{3}{*}{ Investigational factors $(K)$} & $K_{1}$ & Completeness in the degree of investigation \\
\hline & $K_{2}$ & Accuracy of investigation \\
\hline & $K_{3}$ & Timely additional investigation \\
\hline \multirow{3}{*}{ Design factors $(S)$} & $S_{1}$ & Integrity of the design contents \\
\hline & $S_{2}$ & Rationality of design calculation \\
\hline & $S_{3}$ & Consideration of the on-site characteristics \\
\hline \multirow{8}{*}{ Technological factors $(J)$} & $J_{1}$ & Workman craft \\
\hline & $J_{2}$ & Safety protection measures \\
\hline & $J_{3}$ & Construction standard processes \\
\hline & $J_{4}$ & Implementation of technical specifications \\
\hline & $J_{5}$ & Safety operations \\
\hline & $J_{6}$ & Construction monitoring \\
\hline & $J_{7}$ & Construction schemes \\
\hline & $J_{8}$ & Construction equipment \\
\hline \multirow{9}{*}{ Managerial factors $(G)$} & $G_{1}$ & Rational construction organization \\
\hline & $G_{2}$ & Effective safety system \\
\hline & $G_{3}$ & Rational process control \\
\hline & $G_{4}$ & Construction command \\
\hline & $G_{5}$ & Cross-construction organization \\
\hline & $G_{6}$ & Information communication \\
\hline & $G_{7}$ & Employee knowledge \\
\hline & $G_{8}$ & Equipment management \\
\hline & $G_{9}$ & Construction supervision \\
\hline \multirow{6}{*}{ Environmental factors $(H)$} & $H_{1}$ & Underground pipelines \\
\hline & $\mathrm{H}_{2}$ & Construction sites \\
\hline & $\mathrm{H}_{3}$ & Weather conditions \\
\hline & $\mathrm{H}_{4}$ & Hydrological conditions \\
\hline & $\mathrm{H}_{5}$ & Geological conditions \\
\hline & $H_{6}$ & Surrounding buildings and structures \\
\hline
\end{tabular}

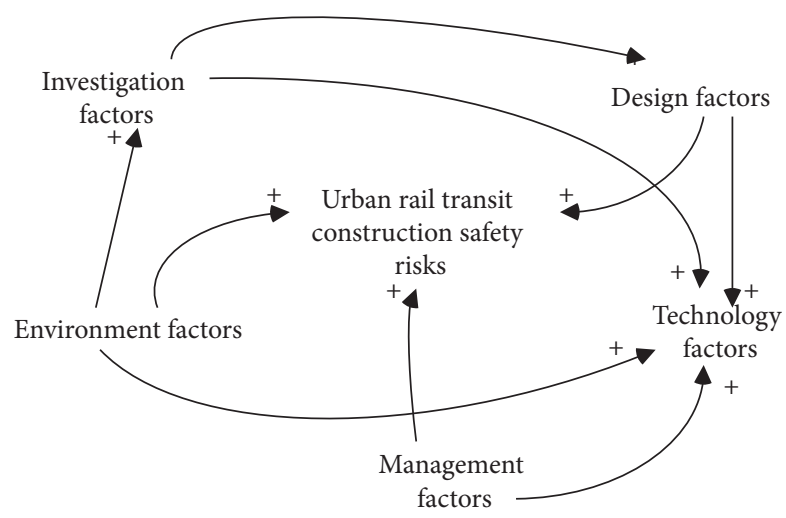

Figure 3: Causal loop diagram of risk factor categories. characteristics $\left(S_{3}\right) \longrightarrow$ rationality of design calculation $\left(S_{2}\right)$, and integrity of the design $\left(S_{1}\right)$ ). A similar analysis was performed for the other three categories. Causal relationships among the 5 categories and 29 factors are displayed in Figure 4 .

4.4. Causal Loop Diagram. Figure 3 depicts the causal loop diagram of risk factor categories, and Figure 4 details the causal loop diagram considering all the risk factors. For instance, design risks are directly influenced by investigation risks. On the other hand, investigational risks are affected by environmental risks. Only positive $(+)$ impacts (magnification effect of interaction) were considered, meaning that the risks were reinforced and diminished corresponding to 


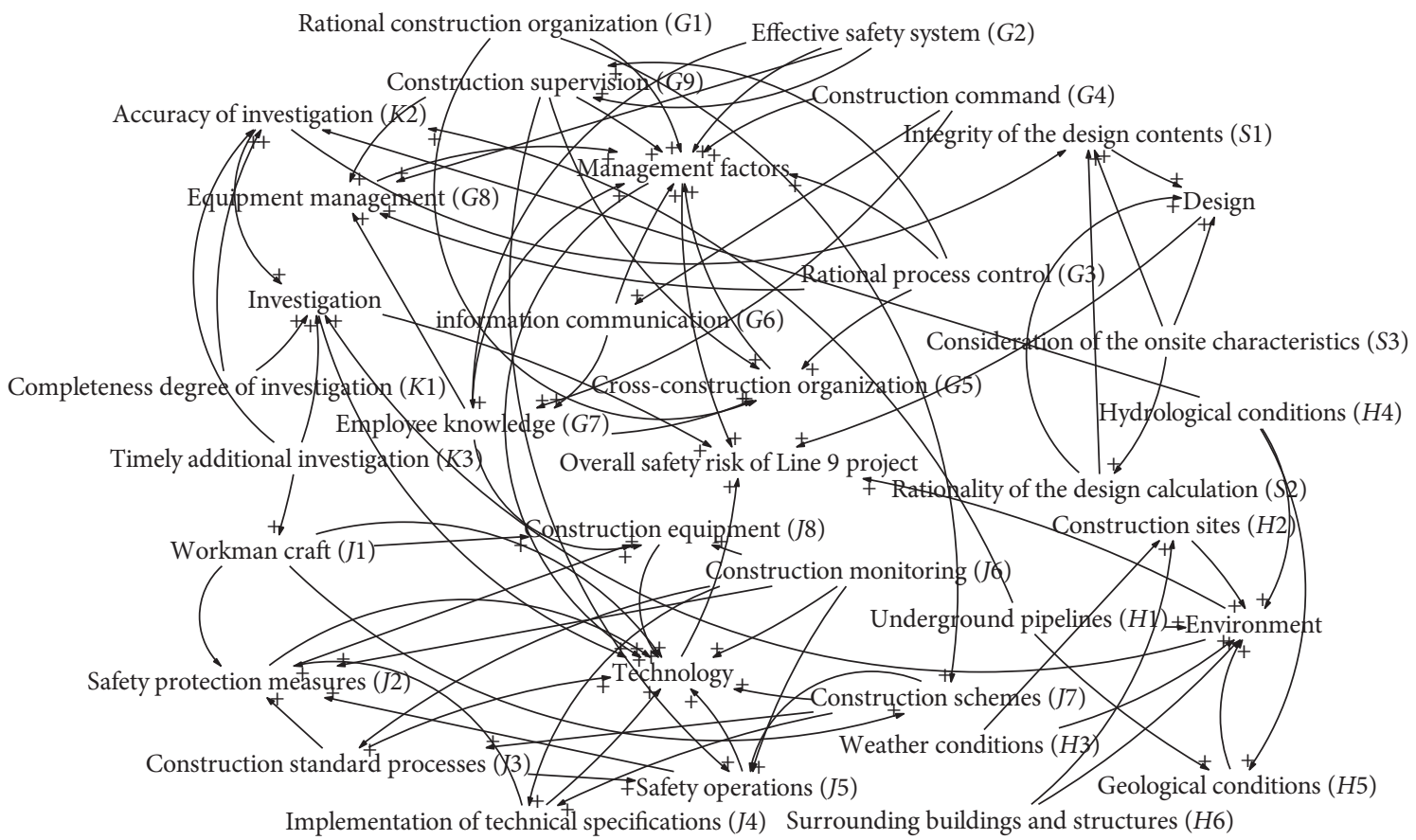

FIgURE 4: Causal loop diagram considering all the risk factors.

their previous factors. Negative influences were not considered in this study as we were focused only on the threat characteristics of risks [57].

4.5. Stock and Flow Diagram. According to the causal loop diagram and the defined calculation formulas, the stock and flow diagram of the SD model was obtained, which is provided in Figure 5. The diagram is organized into five sections based on the five risk categories to facilitate the understanding of the safety risk system.

4.6. Simulation Results. The planned construction duration of the Shenzhen Line 9 project is four years. Considering this, the time boundary of the model was set as 48 months $(T=48)$ and the time-step was decided as 1 month $(\Delta t=1)$. The simulation was conducted using the VENSIM software.

Fifteen engineers and managers at the site were invited to access the likelihood $(L)$, exposure to the environment $(E)$, and consequence $(C)$ value of each risk factor. Their weights (QZ) were evaluated using the analytic hierarchy process (AHP) [11]. Further, the risk value of each risk factor was calculated using equation (1). The initial risk state level of Line $9\left(\mathrm{SL}\left(t_{0}\right)\right)$ was obtained based on equations (5) and (6):

$$
\begin{array}{r}
\mathrm{QZ}=\left\{\mathrm{QZ}_{K}, \mathrm{QZ}_{S}, \mathrm{QZ}_{J}, \mathrm{QZ}_{G}, \mathrm{QZ}_{H}\right\}=\{0.24,0.11,0.14,0.38,0.13\}, \\
\mathrm{SLI}=\{\mathrm{SLK}, \mathrm{SLS}, \mathrm{SLJ}, \mathrm{SLG}, \mathrm{SLH}\}=\{68,75,65,76,76\}, \\
\operatorname{SL}\left(t_{0}\right)=72.5 .
\end{array}
$$

To obtain the transfer coefficient, safety risk assessment based on the LEC method was carried out on a regular basis (once every two weeks). The assessment data were distributed discretely; therefore, the risk transmission among the factors was expressed using the table function, for which, determining the $x$ and $y$ coordinates was a prerequisite. Here, the $x$ coordinate is the analysis time in months and the $y$ coordinate is the value of the table function, which can be obtained by using the safety risk assessment results divided by the time interval. For example, the transfer coefficient of $\mathrm{RK}_{3}$ to $\mathrm{RK}_{1}$ can be expressed as $[(0,0)-(48,1.5)],(0,1.0),(4,0.1 .1),(8,1.4)$, $(12,1.2),(16,1.3),(20,1.7),(24,1.6),(30,1.1),(36,0.9)$, $(42,0.7),(48,0.8)$. Later, the change rate of each risk factor can be obtained using equations (2) and (3):

Furthermore, the safety state level of the system and the change rate of each factor were acquired from equations (4)-(7). In addition, the sensitivity values of risk factors were quantified from equation (8).

\section{Discussions}

5.1. Prediction of the Safety Risk State Level. Figure 6 plots the developing trend of the SL for the Line 9 project. As depicted in the figure, the $S L$ curve gradually increases from the initial point (SL $\left(t_{0}\right)=72.5$ ) during the beginning of construction; it then fluctuates slightly during the middle stage; and finally, it decreases at the end of the construction period. The escalation during the earlier stages is caused by the unaddressed issues in investigation and the design defects. Meanwhile, the problems of inadequate construction technology, inappropriate operations, and inefficient management are gradually exposed, which cause continuous rise in risk. When the safety risk reaches a certain level (e.g., 77.5 at the point of the $24^{\text {th }}$ month), it drops gently owing to the risk control measures, which include additional geological exploration, enhancement of construction monitoring, and adjustment of construction 


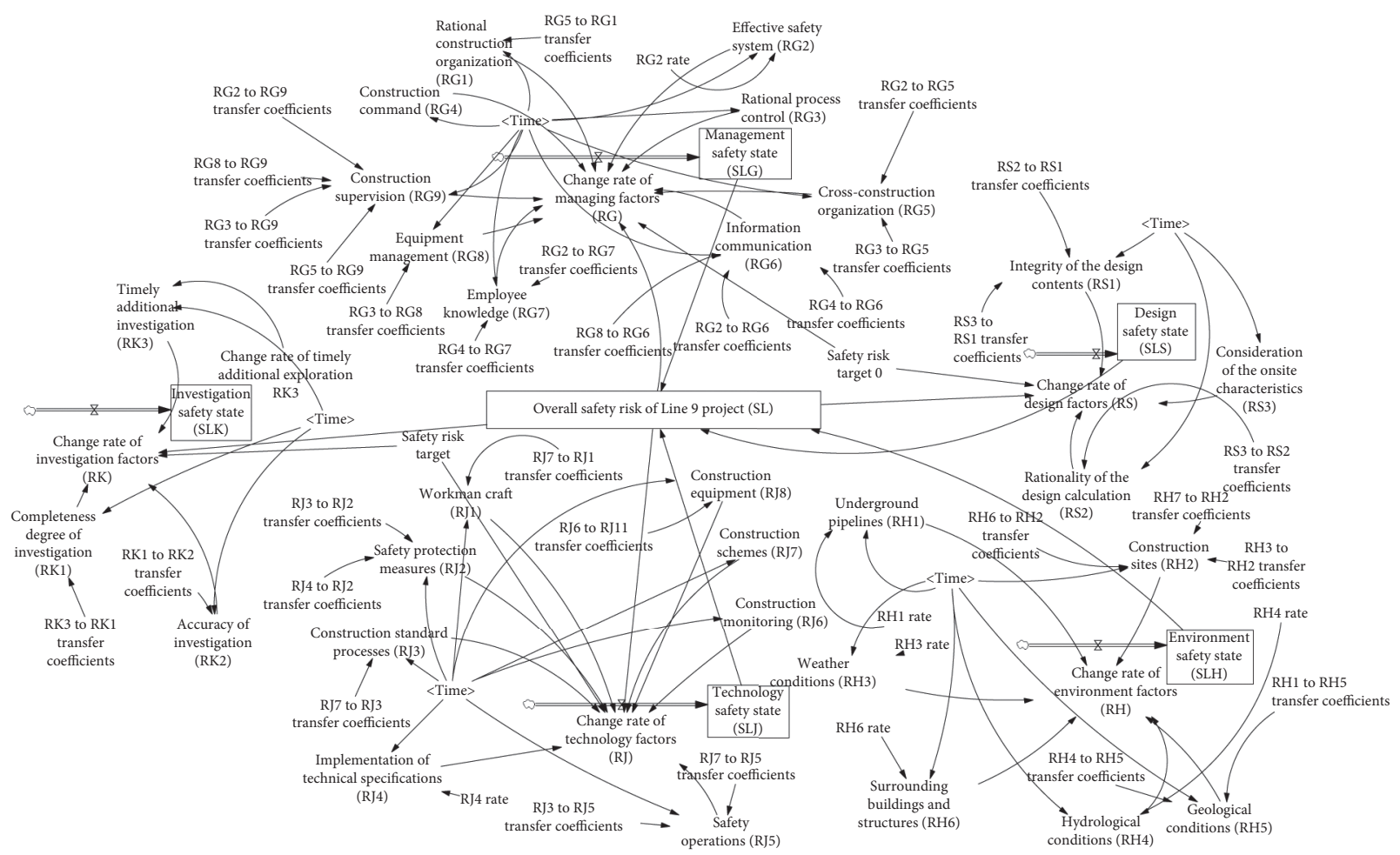

FIgURE 5: Stock and flow diagram of safety risks.

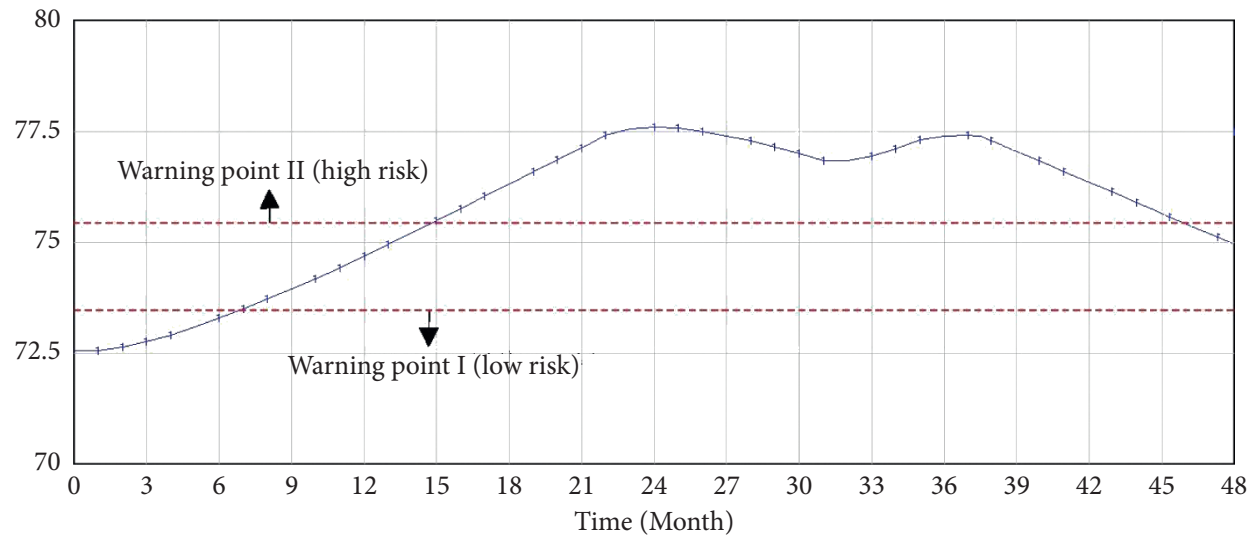

FIGURE 6: Developing trend of the overall safety state level for Line 9 project.

schemes. Further, the safety risk state may increase again when risk control measures are either completed or weakened. The safety level bounces with round-by-round risk control measures until the end of the project.

In addition, the curve also helps with the development of risk control strategies; that is, it requires an efficient cost strategy for controlling the project's safety risks within an acceptable range. Multilevel warning points were set for hierarchical precaution. In the Line 9 project (Figure 6), two points were set, which were 74 and 76 . The lower point indicated that the safety risk state was low; however, effective control measures should be taken to avoid risk increasing. The upper limit of the range represented the maximum risk level that the project manager could afford. It was a warning point that an accident might occur from the project manager's perception. The lower and upper limits of the safety risk level were determined by the project manager and varied with the manager's risk attitude.

Furthermore, the developing trend of each risk category was observed as well. For example, Figure 7 plots the variations in investigational and technological factors. Figure 7 (a) depicts a gradual downward trend. As the project progresses, preliminary, detailed, and additional investigations during the construction could gradually reveal the surrounding environment and help to reduce 


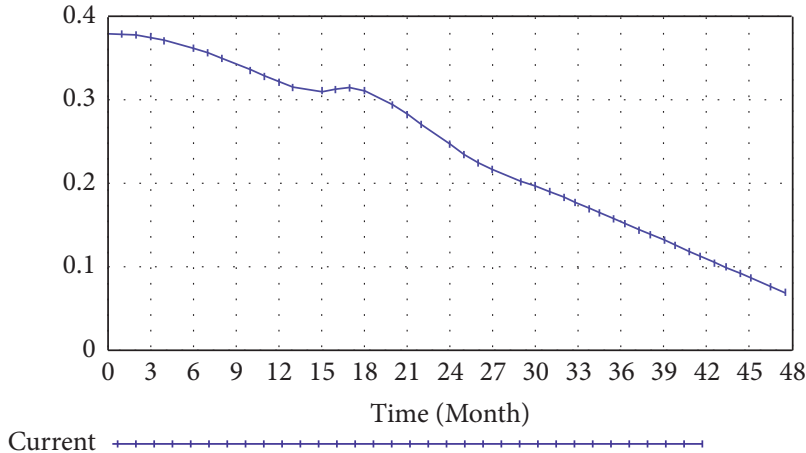

(a)

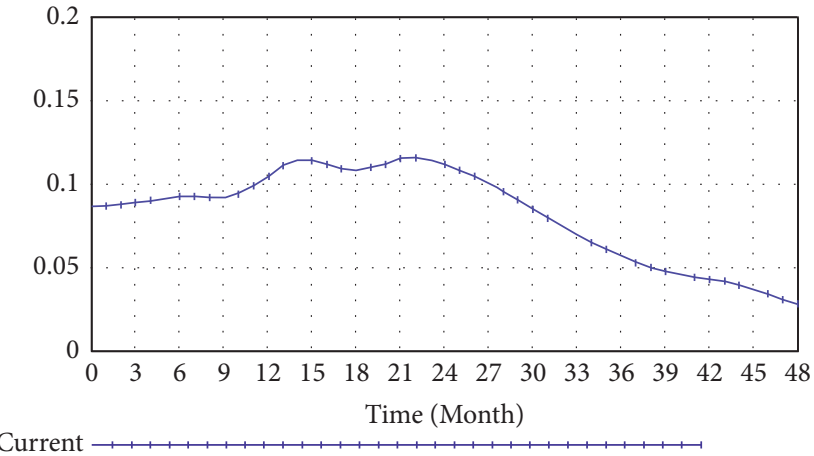

(b)

FIGURE 7: Developing trend of risk categories. (a) Developing trend of investigation factors. (b) Developing trend of technology factors.

TABLE 4: Top 10 sensitive safety risk factors.

\begin{tabular}{lccc}
\hline Number & Influencing factor & Code & Sensitivity value \\
\hline 1 & Completeness degree of investigation & $\mathrm{K}_{1}$ & 0.008058875 \\
2 & Timely additional investigation & $K_{3}$ & 0.006833984 \\
3 & Effective safety system & $G_{2}$ & 0.003228142 \\
4 & Accuracy of investigation & $K_{2}$ & 0.002817599 \\
5 & Construction command & $G_{4}$ & 0.00268383 \\
6 & Consideration of the on-site characteristics & $S_{3}$ & 0.002244121 \\
7 & Information communication & $G_{6}$ & 0.001952145 \\
8 & Implementation of technical specifications & $S_{4}$ & 0.001746833 \\
9 & Rationality of design calculation & $S_{2}$ & 0.00149557 \\
10 & Construction supervision & $G_{9}$ & 0.00147849 \\
\hline
\end{tabular}

the safety risks. Figure 7(b) shows the change curve of the technological factors. The curve first rises and then falls. During the beginning phase of the project, less schedule pressure and construction difficulties are encountered. As deep excavations and underground tunnel constructions begin, the construction difficulty level gradually increases. It reduces only after the completion of the exteriorprotected constructions. The developing trend curve also indicates the important activities that may cause a peak in the curve. For example, as shown in Figure 7, the factors of investigation and technology both show a temporary upward trend at the $18^{\text {th }}$ month. This is because the shield needs to pass through an existing line. Therefore, crossing the existing lines at the $18^{\text {th }}$ month was considered a highrisk event.

5.2. Sensitivity Analysis of Safety Risk Factors. The sensitivity of each risk factor was determined to plan the risk control strategies according to equation (8). Table 4 provides the top 10 sensitive safety risk factors. The changes in these factors have the greatest impact on the SL. Therefore, it is recommended to adopt strong risk control measures for weakening these risk factors. Managers can optimize risk control strategies based on sensitivity analysis. Furthermore, Table 4 also shows that the risk factors generated in the investigation and design stages (e.g., $K_{1}, K_{3}, K_{2}, S_{3}$, and $S_{2}$ ) possess highly sensitive values. This is because these preconstruction risk factors may lurk and wait to be triggered in the construction stage.

\section{Conclusion}

Mega construction projects are inherently high-risk and complex. To improve the safety state level and avoid accidents, construction safety risks have been analyzed using several quantified models. However, few of them can simulate the realtime variation in safety factors and its consequent dynamic influence on safety state. This study proposed a hybrid approach for the dynamic simulation of safety risks in mega construction projects. A three-stage procedure for safety risk identification was provided in order to extract risk factors and causal relationships from accident reports, standards, and regulations. This approach provides an efficient alternative for conventional risk identification that uses large-scale questionnaires and expert interviews. To overcome the difficulty of quantifying variables and equations in the SD model, the LEC method was utilized to define the changes in risk factors over time. The combined method simplifies the collection of the input data of the SD model; consequently, it provides a practical framework to simulate and predict the safety state dynamically for complex mega construction projects. Moreover, this hybrid approach also helps with the selection of targeted and effective risk control strategies. Through this dynamic simulation model, managers can develop decisionmaking skills and conduct experiments. 
Only the positive effects of interactions were considered in the case study because the traditional view of safety risks represents loss and adverse consequences. The negative effects of interactions, given the good side of risks, can be studied in the future. In addition, the identification of risk factors was time-consuming and limited by the experts' knowledge. Therefore, future work could seek to apply data mining and knowledge discovery technology to extract the factors and causal relationships from the existing documents.

\section{Data Availability}

The data used to support the findings of this study are included within the article.

\section{Conflicts of Interest}

The authors declare no conflicts of interest.

\section{Acknowledgments}

The authors thank the researcher fellow Professor Wang and Dr. Jie Li of China University of Mining and Technology for their helpful suggestions in risk factor identification and causal relationship generation. Also, the authors extend special appreciation to safety managers and engineers of the Line 9 contractors for assistance in gathering field data. This research was supported by the Jiangsu Collaborative Innovation Center for Building Energy Saving and Construction (Grant no. SJXTBZ1704) and the National Natural Science Foundation of China Grant no. 71901206).

\section{References}

[1] B. Flyvbjerg, N. Bruzelius, and W. Rothengatter, Megaprojects and Risk: An Anatomy of Ambition, Cambridge University Press, Cambridge, UK, 2003.

[2] L. Ma and H. Fu, "Exploring the influence of project complexity on the mega construction project success: a qualitative comparative analysis, (qca) method," Engineering, Construction and Architectural Management, vol. 27, no. 9, pp. 2429-2449, 2020.

[3] A. Sanchez-Cazorla, R. Alfalla-Luque, and A. I. Irimia-Dieguez, "Risk identification in megaprojects as a crucial phase of risk management: a literature review," Project Management Journal, vol. 47, no. 6, pp. 75-93, 2016.

[4] Q. Qian and P. Lin, "Safety risk management of underground engineering in China: progress, challenges and strategies," Journal of Rock Mechanics and Geotechnical Engineering, vol. 8, no. 4, pp. 423-442, 2016.

[5] X. Zhao, Y. Feng, D. Yang, and D. Zhao, "Advanced management in civil engineering projects," Advances in Civil Engineering, vol. 2018, Article ID 4901707, 2 pages, 2018.

[6] N. J. Smith, T. Merna, and P. Jobling, Managing Risk in Construction Projects, John Wiley \& Sons, Hoboken, NY, USA, 2014.

[7] X. Yang and S. Haugen, "Implications from major accident causation theories to activity-related risk analysis," Safety Science, vol. 101, pp. 121-134, 2018.

[8] J. Li, J. Wang, N. Xu, Y. Hu, and C. Cui, "Importance degree research of safety risk management processes of urban rail transit based on text mining method," Information, vol. 9, no. 2, p. 26, 2018.

[9] X. Na, "Analysis on relationships of safety risk factors in metro construction," Journal of Engineering Science \& Technology Review, vol. 9, no. 5, 2016.

[10] M. Hallowell, B. Esmaeili, and P. Chinowsky, "Safety risk interactions among highway construction work tasks," Construction Management and Economics, vol. 29, no. 4, pp. 417-429, 2011.

[11] Y.-C. Kuo and S.-T. Lu, "Using fuzzy multiple criteria decision making approach to enhance risk assessment for metropolitan construction projects," International Journal of Project Management, vol. 31, no. 4, pp. 602-614, 2013.

[12] M. Ahmadi, K. Behzadian, A. Ardeshir, and K. kapelan, "Comprehensive risk management using fuzzy FMEA and MCDA techniques in highway construction projects," Journal of Civil Engineering and Management, pp. 1-11, 2016.

[13] L. Zhang, M. J. Skibniewski, X. Wu, Y. Chen, and Q. Deng, “A probabilistic approach for safety risk analysis in metro construction," Safety Science, vol. 63, pp. 8-17, 2014.

[14] H. Shirouyehzad, M. Khodadadi-Karimvand, and R. Dabestani, "Prioritizing critical success factors influencing safety, using TOPSIS," International Journal of Business and Social Science, vol. 2, no. 20, 2011.

[15] C. Balocco and P. Capone, "Construction site risk analysis based on Shannon entropy: a case study application," WIT Transactions on the Built Environment, vol. 82, p. 11, 2005.

[16] N. Sadeghi, A. R. Fayek, and W. Pedrycz, "Fuzzy monte carlo simulation and risk assessment in construction," ComputerAided Civil and Infrastructure Engineering, vol. 25, no. 4, pp. 238-252, 2010.

[17] R. Dogbegah, D. Owusu-Manu, and K. Omoteso, "A principal component analysis of project management competencies for the ghanaian construction industry," Australasian Journal of Construction Economics and Building, vol. 11, no. 1, pp. 26-40, 2011.

[18] B.-G. H. Tengyuan Chang, X. Deng, and X. Zhao, "Identifying political risk management strategies in international construction projects," Advances in Civil Engineering, vol. 2018, p. 11, 2018.

[19] V. Anderson and L. Johnson, Systems Thinking Basics, Pegasus Communications Cambridge, Cambridge, MA, USA, 1997.

[20] H. Ren, "Risk lifecycle and risk relationships on construction projects," International Journal of Project Management, vol. 12, no. 2, pp. 68-74, 1994.

[21] J. F. Al-Bahar and K. C. Crandall, "Systematic risk management approach for construction projects," Journal of Construction Engineering and Management, vol. 116, no. 3, pp. 533-546, 1990.

[22] Y. Li, Y. Ning, and W. T. Chen, "Critical success factors for safety management of high-rise building construction projects in China," Advances in Civil Engineering, vol. 2018, Article ID 1516354, 15 pages, 2018.

[23] A. J. Tomarken and N. G. Waller, "Structural equation modeling: strengths, limitations, and misconceptions," $A n$ nual Review of Clinical Psychology, vol. 1, no. 1, pp. 31-65, 2005.

[24] C. Zhou, L. Ding, M. J. Skibniewski, H. Luo, and S. Jiang, "Characterizing time series of near-miss accidents in metro construction via complex network theory," Safety Science, vol. 98, pp. 145-158, 2017.

[25] D.-M. Zhang, F. Du, H. Huang, F. Zhang, B. M. Ayyub, and M. Beer, "Resiliency assessment of urban rail transit networks: 
shanghai metro as an example," Safety Science, vol. 106, pp. 230-243, 2018.

[26] Z. Zhou and J. Irizarry, "Integrated framework of modified accident energy release model and network theory to explore the full complexity of the hangzhou subway construction collapse," Journal of Management in Engineering, vol. 32, no. 5, Article ID 05016013, 2016.

[27] S. Seker and E. Zavadskas, "Application of fuzzy DEMATEL method for analyzing occupational risks on construction sites," Sustainability, vol. 9, no. 11, p. 2083, 2017.

[28] L. Wu, H. Bai, C. Yuan, and C. Xu, "FANPCE technique for risk assessment on subway station construction," Journal of Civil Engineering and Management, vol. 25, no. 6, pp. 599616, 2019.

[29] F. Afzal et al., "A review of artificial intelligencebased risk assessmentmethods for capturingcomplexity-risk interdependenciesCost overrun in construction projects," International Journal of ManagingProjects in Busines, 2019.

[30] L. Zhang, X. Wu, M. J. Skibniewski, J. Zhong, and Y. Lu, "Bayesian-network-based safety risk analysis in construction projects," Reliability Engineering \& System Safety, vol. 131, pp. 29-39, 2014.

[31] W. Liu, S. Zhai, and W. Liu, "Predictive analysis of settlement risk in tunnel construction: a bow-tie-bayesian network approach," Advances in Civil Engineering, vol. 2019, pp. 1-19, 2019.

[32] S. M. Hatefi and J. Tamošaitienè, "An integrated fuzzy DEMATEL-fuzzy ANP model for evaluating construction projects by considering interrelationships among risk factors," Journal of Civil Engineering and Management, vol. 25, no. 2, pp. 114-131, 2019.

[33] C. Zhou and L. Y. Ding, "Safety barrier warning system for underground construction sites using Internet-of-Things technologies," Automation in Construction, vol. 83, pp. 372389, 2017.

[34] M. Li, H. Yu, H. Jin, and P. Liu, "Methodologies of safety risk control for China's metro construction based on BIM," Safety Science, vol. 110, pp. 418-426, 2018.

[35] H. Hadj-Mabrouk, "Contribution of artificial intelligence to risk assessment of railway accidents," Urban Rail Transit, vol. 5, no. 2, pp. 104-122, 2019.

[36] L. Deng, M. Zhong, L. Liao, L. Peng, and S. Lai, "Research on safety management application of dangerous sources in engineering construction based on BIM technology," Advances in Civil Engineering, vol. 2019, Article ID 7450426, 10 pages, 2019.

[37] Y. Shin, "Application of stochastic gradient boosting approach to early prediction of safety accidents at construction site," Advances in Civil Engineering, vol. 2019, Article ID 1574297, 9 pages, 2019.

[38] R. G. Coyle and R. G. Coyle, Management system dynamics, Wiley, Chichester, UK, 1977.

[39] Y. M. Goh and P. E. D. Love, "Methodological application of system dynamics for evaluating traffic safety policy," Safety Science, vol. 50, no. 7, pp. 1594-1605, 2012.

[40] A. De Marco, C. Rafele, and M. J. Thaheem, "Dynamic management of risk contingency in complex design-build projects," Journal of Construction Engineering and Management, vol. 142, no. 2, Article ID 04015080, 2016.

[41] P. E. D. Love, G. D. Holt, L. Y. Shen, H. Li, and Z. Irani, "Using systems dynamics to better understand change and rework in construction project management systems," International Journal of Project Management, vol. 20, no. 6, pp. 425-436, 2002.
[42] L. Gao and Z.-Y. Zhao, "System dynamics analysis of evolutionary game strategies between the government and investors based on new energy power construction public-privatepartnership , (PPP) project," Sustainability, vol. 10, no. 7, p. 2533, 2018.

[43] F. Nasirzadeh, H. Mazandaranizadeh, and M. Rouhparvar, "Quantitative risk allocation in construction projects using cooperative-bargaining game theory," International Journal of Civil Engineering, vol. 14, no. 3, pp. 161-170, 2016.

[44] H. Etemadinia and M. Tavakolan, "Using a hybrid system dynamics and interpretive structural modeling for risk analysis of design phase of the construction projects," International Journal of Construction Management, pp. 1-20, 2018.

[45] M. Khanzadi, F. Nasirzadeh, and M. Alipour, "Integrating system dynamics and fuzzy logic modeling to determine concession period in BOT projects," Automation in Construction, vol. 22, pp. 368-376, 2012.

[46] B. H. W. Guo, Y. M. Goh, and K. Le Xin Wong, "A system dynamics view of a behavior-based safety program in the construction industry," Safety Science, vol. 104, pp. 202-215, 2018.

[47] F. Nasirzadeh, A. Afshar, M. Khanzadi, and S. Howick, "Integrating system dynamics and fuzzy logic modelling for construction risk management," Construction Management and Economics, vol. 26, no. 11, pp. 1197-1212, 2008.

[48] F. Wang, L. Ding, P. E. D. Love, and D. J. Edwards, "Modeling tunnel construction risk dynamics: addressing the production versus protection problem," Safety Science, vol. 87, pp. 101115, 2016.

[49] J. Zhao, R. Pang, and S. Zhang, "Human reliability evaluation of assembly production line," International Journal of Performability Engineering, vol. 14, no. 12, pp. 3109-3117, 2018.

[50] D. Peibin, G. Hailin, and L. Xiaolei, "Safety risk analysis on crossing task in the construction of hydropower station," Journal of Anhui Agricultural Sciences, vol. 37, no. 16, pp. 76-78, 2009.

[51] X. Zeng, H. Yin, and Y. Li, “Application of modified LEC method in the large municipal bridge construction hazard evaluation," in Proceedings of 2015 8th International Symposium on Computational Intelligence and Design, (ISCID), December 2015.

[52] C. Li, G. Lu, and P. Li, "Risk element transmission model of construction project chain based on system dynamic," Research Journal of Applied Sciences, Engineering and Technology, vol. 5, no. 4, pp. 1407-1412, 2013.

[53] A. Maryani, S. Wignjosoebroto, and S. G. Partiwi, "A system dynamics approach for modeling construction accidents," Procedia Manufacturing, vol. 4, pp. 392-401, 2015.

[54] X. Net, "The 13th five-year plan for economic and social development of the people's republic of china," 2016, http:// www.xinhuanet.com//politics/2016lh/2016-03/17/c_ 1118366322.htm.

[55] Mohurd, "Code for risk management of underground engineering construction in urban rail transit, in GB 50652-2011," Ministry of Housing and Urban-Rural Development, Beijing, China, 2011.

[56] H. Yan, C. Gao, H. Elzarka, K. Mostafa, and W. Tang, "Risk assessment for construction of urban rail transit projects," Safety Science, vol. 118, pp. 583-594, 2019.

[57] K. Buyens, B. De Win, and W. Joosen, "Empirical and statistical analysis of risk analysis-driven techniques for threat management," in Proceedings of he Second International Conference on Availability, Reliability and Security, (ARES'07), April 2007. 